\title{
Evaluation of Brooke Formula Plus Dopamine in Burn Resuscitation
}

\author{
Buddhike S. H. Indrasena ${ }^{1}$ MBBS, MRCSEd, MSc, MS \\ Nalin S. S. K. Jayasinghe ${ }^{2}$ MD \\ Lakmal B. Doratiyawa ${ }^{2}$ MBBS \\ ${ }^{1}$ Consultant General Surgeon, Department of General Surgery, Batticaloa General Hospital \\ (Teaching), Sri Lanka \\ ${ }^{2}$ Senior House Officer, Department of General Surgery, Batticaloa General Hospital (Teaching), Sri \\ Lanka
}

\begin{abstract}
:
Objective: Best fluid regime in burn resuscitation is debatable. Recent evidence supports the use of colloids. This study analyzes the effectiveness of Brooke formula.

Method: Brooke formula was used exclusively over 2.5 years. Patients were followed up until discharge. Results were compared with another unit of the same institution that used Parkland formula. Overall mortality as well as the mortality and morbidity within first 72 hours of a highly selected group of patients without adverse prognostic factors were analysed. All adult patients above 15 years of age admitted with burns more than 15\% were recruited. Patients with burns less than $40 \%$ and age below 60 years without co-morbid factors were included in the highly selected group. Adequacy of resuscitation was assessed by urine output. Oliguric patients received extra amounts of fluid and renal dose dopamine. Main outcome measures were mortality and anuria. Mortality was assessed under two categories; during the first 72 hours of a highly selected group of patients and overall mortality of the unit.

Results: Sample size was 42. Twenty-eight patients had favourable prognostic factors. Overall mortality before discharge from hospital was $24 \%$. In total, $68 \%$ developed urine output less than $30 \mathrm{ml} / \mathrm{h}$. There were no deaths in the highly selected group within the first 72 hours. When mortality was compared with the mortality of the comparable unit the difference was not statistically significant: $(P$-value $=0.4467)$, Odds ratio 1.66 (CI 1.00 to 2.73). Except in the case of patients who died, the patients who developed oliguria recovered without going into anuria when dopamine was started together with increasing fluid infusion rate.

Conclusion: Brooke formula is an effective alternative to Parkland formula. Nevertheless, urine output has to be monitored judiciously and treated accordingly. Dopamine may have a place to maintain urine output in burns.
\end{abstract}

Keywords: Brooke formula, renal dose dopamine, Parkland formula

\section{Introduction}

In 1940s and 1950s, as low as $25 \%$ of total body surface area (TBSA) burns carried $100 \%$ mortality in above 50-year olds. ${ }^{[1]}$ Nowadays, $50 \%$ survival can be achieved in young adults even with $80 \%$ TBSA burns. ${ }^{[2]}$ The improved outcome could be attributed partly to the development of fluid resuscitation formulas in 1950s: Evans' formula in1952 and Brooke formula in1953. According to Clark and Hanson, during 1943-1947 period $69 \%$ of deaths occurred within first 48 hours; ${ }^{[1]}$ this declined to $19 \%$ during 1952-1956 period with the introduction of Evans and Brooke formulae. Muir-Barclay formula and Parkland formula were introduced much later in 1962 and 1968, respectively. This means the improved outcome from major burns was noticed well before the advent of the Parkland formula.

Although the mortality from burns declined sharply with the introduction of Evans' and Brooke formulae, these two formulae are hardly used nowadays for burn resuscitation. ${ }^{[3]}$ Instead, the Parkland formula that was introduced much later in 1960 s is widely used. ${ }^{[4]}$

\section{Methodology}

This author is among the few clinicians who employ Brooke formula in burn resuscitation. Further, the use of renal dose dopamine is also his favourite to combat impending acute renal failure in hypovolaemic shock.

In this study, the fluid requirements were calculated as follows: 
In the first $24 \mathrm{~h}$ : Ringer's Lactate at $1.5 \mathrm{ml} / \mathrm{kg} / \%$ burn + colloids at $0.5 \mathrm{ml} / \mathrm{kg} / \%$ burn + plus $2000 \mathrm{ml}$ $5 \%$ glucose in water

In second $24 \mathbf{h}$ : Half the volume of crystalloids and colloid calculated for the first 24 hours + the same amount of glucose in water

Fresh frozen plasma (FFP) was used as colloid transfusion, and was given as boluses every 6-8 hours. After 48 hours, fluid requirements were calculated as per the maintenance requirement. Infusion rate was adjusted according to the hourly urine output. The infusion rate of crystalloids was increased or decreased according to the urine output that was less than $30 \mathrm{ml} / \mathrm{h}$ or more than $50 \mathrm{ml} / \mathrm{h}$, respectively. In addition, whenever the urine output dropped below $30 \mathrm{ml} / \mathrm{h}$ renal dose Dopamine $(4 \mu \mathrm{g} / \mathrm{kg} / \mathrm{min})$ was started. The sole purpose of adding low dose dopamine (renal dose dopamine) was to make use of diuretic effect of dopamine (to maintain blood pressure the desired dose of dopamine is higher in the range of $5-10 \mu \mathrm{g} / \mathrm{kg} / \mathrm{min}$ ). Patients were kept nil by mouth during the first 48 hours.

The effectiveness of the formula was assessed in two ways.

1. The overall mortality of the cohort was compared with the total mortality of the sister unit of the same institution that employed Parkland formula.

2. The effectiveness after excluding the factors that could cause death unrelated to the type of fluid regime used. The factors that could cause death unrelated to the fluid regime used were assumed to be the adverse prognostic factors that had been identified by other studies. ${ }^{[5,6]}$ Out of all known such adverse prognostic factors, only the age above 60 years, TBSA burned more than $40 \%$ and uncontrolled co-morbid diseases could be considered in this study for practical reasons. Patients who did not have such adverse factors were separately analysed for mortality within the first 72 hours post burn. To exclude the deaths caused by sepsis, ${ }^{[7]}$ the observational period was restricted to first 72 hours. ${ }^{[8]}$

\section{Outcome}

The total number of patients managed during the study period was 42 . Ten (24\%) were males and 32 were females. Four patients were aged above 70 years, and the oldest patient was 90 years old. Four patients had one or more stable co-morbid factors viz. hypertension (two), ischemic heart disease (one), bronchial asthma (one) and diabetes mellitus (two). Three patients were pregnant, one in first trimester and the other two, in second trimester. One pregnancy ended up in spontaneous abortion. The foetuses of the other two were viable at discharge of the patient. In addition, one patient was under treatment for depression. Three males had been consuming alcohol regularly.

Out of 42 patients only 28 patients (67\%), 22 females and six males, did not have any of the adverse prognostic factors outlined above (age equal or less than 60 years, surface area burned equal or less than $40 \%$ and major uncontrolled co-morbid factors). It was not possible to identify the patients who had inhalational burns with the facilities available in the institution.

As shown in Table 1, the majority of the patients were young adults in the 21-30 year age range. The median age was 29 years, the range being from 15 to 90 years. Almost all (86\%) patients were below 60 years of age.

The mean and median of the TBSA burned was 36\% and 30\%, respectively; the lowest was $15 \%$ and the highest was $90 \%$ (Table 2). The number of patients with burns below $40 \%$ TBSA was 28 (67\%).

One case sustained burns due to electrocution. Five cases were due to hot water burns, and all others sustained burns caused by flame mainly due to kerosene oil. Ten cases were associated with attempted suicide, one case was attempted homicide and the remaining 31 were accidental.

It was noticed that $69 \%$ of the casualties presented within four hours of injury and seven patients presented after six hours of injury (Table 3). The range was between 45 minutes and 16 hours. Patients who presented late were the transfers from other hospitals. Most of them had been resuscitated before transferring to the hospital. At the time when the fluid requirement was calculated for them, only the additional volume was given after subtracting the volume already given by the previous institution.

All together, 10 patients died (mortality 24\%). Out of 28 patients who did not have adverse prognostic factors (i.e. age above 60 years, surface area burned more than $40 \%$ and presence of major uncontrolled comorbid factors), 19 patients, i.e. $68 \%$, developed urine output $<30 \mathrm{ml} / \mathrm{h}$ requiring initiation of renal dose dopamine. On initiation of dopamine and increasing fluid infusion rate, all of them recovered fully without going into acute renal failure or death during the first 72 hours.

\section{Statistical Analysis}

In the unit this study was performed the overall mortality was $24 \%$ (10 out of 42). Although the figure is quite high, it is still within the range of mortality rates reported elsewhere $(1-34 \%)$. However, all these 
deaths were related to either the presence of adverse prognostic factors or sepsis. There was not a single death occurring during the first 72 hours of the group who had favourable prognostic factors.

The overall mortality was compared with the mortality rate of the companion unit of the same hospital (Table 4). ${ }^{[9]}$ The difference was not statistically significant $(P=0.4467$, Chi-square test). The odds ratio was 1.6562. The confidence interval of the odds ratio was 1.0044 to 2.7311. Since the confidence interval of the odds ratio includes one, the difference of effect size, if any, is negligible. Therefore, the difference in mortality rate between the two units is neither clinically important nor statistically significant.

The mortality rate in the sample that used Brooke formula plus dopamine was not statistically different from the mortality rate of the unit that used Parkland formula. Despite the fact that the commonest burn resuscitation formula used worldwide is Parkland formula it appears that, the Brooke formula is no worse than Parkland formula.

\section{Discussion}

The outcome of this study has been assessed in two angles: the overall mortality and the mortality of patients with favourable prognostic factors. The overall mortality figure is not apparently different from other published studies. However, the overall mortality is not much useful when assessing the effectiveness of a fluid regime. This is because irrespective of the quality of medical care and the type of fluid resuscitation used, the patients who have major adverse factors are bound to die. For example, it is unreasonable to attribute death of an 80 -year-old patient with $50 \%$ burns to the resuscitation formula. It is unlikely that we would ever find a formula to salvage such patients. This is a major drawback of most of the published studies comparing the effectiveness of resuscitation formula. The effectiveness of a resuscitation formula can only be assessed after excluding such necessarily fatal injuries.

In the analysis, it was found that there was no mortality when none of the adverse prognostic factors was absent. This outcome can reasonably be attributed to the effect of the fluid regime because the risks unrelated to the fluid regime have been excluded. By considering the deaths that occurred during the first 72 hours, the deaths due to sepsis that are bound to occur after 48 hours have been excluded. As a result, the selected group of patients accurately represent the risk due to the type of fluid regime used for resuscitation. Because there was no mortality in the group of patients who did not have adverse prognostic factors during the first 72 hours, it is reasonable to conclude that the Brooke formula could safely be used to resuscitate burn patients.

The only problem that was observed during the study was a high rate of oliguria. Oliguria in burn patients can be due to factors other than hypovolaemia. Therefore, it is not always reasonable to transfuse fluid guided by urine output. We addressed this point by adding renal dose dopamine in addition to increasing intravenous fluid. Although, there are controversial opinions regarding the effectiveness of renal dose dopamine, there is no other suitable alternative to use instead. Therefore, we used the best renal salvage medicine available to treat oliguria. It is hard to find studies proving that renal dose dopamine either prevents or cures acute renal failure. ${ }^{[10,11]}$ In the absence of scientific evidence, renal dose dopamine is going out of favour from most units nowadays. However, pharmacologically, low dose dopamine does have renal vasodilator effect. ${ }^{[12]}$ Dopamine increases excretion of sodium in urine. Therefore, theoretically, low dose dopamine promotes renal blood flow increasing the glomerular filtration rate and urine output. Giving intravenous fluid alone carries the risk of doing over-transfusion resulting in fluid overload. Patients who receive only intravenous fluid to correct oliguria often develop peripheral and central oedema without correcting oliguria.

Despite its unpopularity, Brooke formula seems to have many advantages over Parkland formula, at least theoretically. Firstly, it uses 50\% less fluid than Parkland formula. This has beneficial effects on limiting transfusion associated complications as a result of preventing fluid creep. Since it uses less fluid it is also useful when resuscitating patients who are at increased risk of developing cardiac failure; this includes patients who are elderly and patients who have documented cardiac and renal disease. Secondly, original Brooke formula uses colloids starting from the first 24 hours. Parkland formula does not recommend giving colloids in the first 24 hours. ${ }^{[13]}$ When looked in to the pathophysiology of development of burn oedema and shock, it is clear that the leakage of plasma proteins plays a prominent role because of increased capillary permeability in the immediate post burn period. ${ }^{[14]}$ However, it must be noted that even the Brooke formula does not replace the total protein loss, but only a fraction of it. The amount of plasma that is given in Brooke formula is much less than the amount of plasma lost in burns. The rate of plasma loss is $4 \mathrm{ml} / \mathrm{kg} / \mathrm{h}$ in a burn exceeding $30 \%$ TBSA. ${ }^{[15]}$ Accordingly, a $50 \mathrm{~kg}$ man with $30 \%$ burns would lose $4800 \mathrm{ml}$ of plasma in 24 hours. In Brooke formula the rate of plasma infusion for a $30 \%$ burn in a $50 \mathrm{~kg}$ man is only $750 \mathrm{ml}$. This amount is much less (only $15 \%$ of the lost) than the total amount of plasma that the patient loses in first 24 hours. Therefore, although colloids are given in Brooke formula the idea is not to replenish total protein loss but to cautiously maintain a fine balance between the plasma oncotic pressure and interstitial oncotic pressure so that the development of interstitial and cellular oedema can be lessened. 


\section{Conclusion}

It is apparent that Brooke formula could be used with the same efficacy as Parkland formula. Renal dose dopamine may prevent oliguria progressing to anuria. Brooke formula is neither worse nor better than Parkland formula when the overall mortality is considered. Nevertheless, theoretically, there may be many other advantages of using Brooke formula over Parkland formula by limiting fluid overload and over-transfusion associated complications.

\section{References}

[1]. Clark AG, Hanson JH. Mortality rates in patients with burns. California Medicine 1958; 89: 210-14

[2]. Pavoni V, Gianesello L, Barboni E. Outcome predictors and quality of life of severe burn patients admitted to intensive care unit. Scand J Trauma Resusc Emerg Med. 2010 Apr 27; 18:24.

[3]. Fakhry SM, Alexander J, Smith D. Regional and Institutional variation in burn care. J Burn Care Rehabil. 1995; 16: 86-90.

[4]. Baker RH, Akhavani MA, Jallali N. Resuscitation of thermal injuries in the United Kingdom and Ireland. J Plast Reconstr Aesthet Surg. 2007; 60: 682-5

[5]. Evans EI, Purnell OJ, Robinett PW, Batchelor A, Martin M. Fluid and electrolyte requirements in severe burns. Annals of Surgery 1952; 135:804-817.

[6]. Ryan CM, Schoenfeld DA, Thorpe WP, Sheridan RL, Cassem EH, Tompkins RG. Objective Estimates of the Probability of Death from Burn Injuries. N Engl J Med 1998; 338:362-6.

[7]. Williams FN1, Herndon DN, Hawkins HK, Lee JO, Cox RA, Kulp GA, et al. The leading causes of death after burn injury in a single pediatric burn center. Critical Care 2009; 13:R183.

[8]. Brusselaers N, Monstrey S, Vogelaers D, Hoste E, Blot S. Severe burn injury in Europe: a systematic review of the incidence, etiology, morbidity, and mortality. Crit Care 2010; 14:R188.

[9]. Pirasath S, Jasotharan V, Jeepara P. Burn injuries in eastern province of Sri Lanka: an analysis and outcome in a tertiary care hospital. The Sri Lanka Journal of Surgery 2013; 2013; 31(2):11-13

[10]. Burton CJ, Thomson CRV. Management options: Can the use of low-dose dopamine for treatment of acute renal failure be justified? Postgrad Med J 1999; 75:269-274.

[11]. McCrory C, Cunningham AJ. Low-dose dopamine: will there ever be a scientific rationale? Br. J. Anaesth. 1997; 78:350-351.

[12]. McNay JL, McDonald RH, Goldberg LI, Davis C. Direct Renal Vasodilatation Produced by Dopamine in the Dog. Circulation Research. 1965; 16: 510-517.

[13]. Haberal M, Abali ES, Karakayali H. Fluid management in major burn injuries. Indian Journal of Plastic Surgery 2010; 43: 29-36.

[14]. Bacomo FK, Chung KK. A primer on burn resuscitation. J Emerg Trauma Shock 2011; 4: 109-113.

[15]. Ibrahim AE, Sarhane KA, Goverman J. Renal dysfunction in burns: a review. Ann Burns Fire Disasters 2013; 26:16-25.

Table 1: Age Distribution

\begin{tabular}{ll}
\hline Age (Years) & Number of cases \\
\hline$<20$ & 9 \\
$21-30$ & 16 \\
$31-40$ & 4 \\
$41-50$ & 2 \\
$51-60$ & 5 \\
$61-70$ & 2 \\
$71-80$ & 2 \\
$81-90$ & 2 \\
Total & 42 \\
\hline
\end{tabular}

Table 2: TBSA burned

\begin{tabular}{ll}
\hline Percentage Burned & Number of cases \\
\hline$<20$ & 11 \\
$21-30$ & 10 \\
$31-40$ & 7 \\
$41-50$ & 7 \\
$51-60$ & 2 \\
$61-70$ & 1 \\
$71-80$ & 3 \\
$81-90$ & 1 \\
\hline
\end{tabular}

Table 3: The distribution of cases according to the time of presentation

\begin{tabular}{ll}
\hline Delay in Presenting to the Specialized Unit & Number of cases \\
\hline Less than 1 hour & 3 \\
$1-<2$ & 8 \\
$2-<3$ & 9 \\
$3-<4$ & 9 \\
$4-<5$ & 2 \\
$5-<6$ & 4 \\
More than 6 & 7 \\
\hline Total & $\mathbf{4 2}$ \\
\hline
\end{tabular}

Table 4: Comparison of mortality of a comparable unit that used Parkland formula

\begin{tabular}{|l|l|l|l|}
\hline & Dead & Alive & Total \\
\hline Test Group (Brooke formula) & 10 & 32 & 42 \\
\hline Control Group (Parkland formula) & 10 & 53 & 63 \\
\hline Total & 20 & 85 & 105 \\
\hline
\end{tabular}

